\title{
ANALISIS POTENSI KAYU BULAT Shorea leprosula DI KABUPATEN KUTAI KARTANEGARA PROVINSI KALIMANTAN TIMUR
}

\author{
Mus Muliadi ${ }^{1}$, Yosep Ruslim², Rochadi Kristiningrum ${ }^{3}$ \\ ${ }^{1}$ Universitas Kartanegara, Jln. Gn. Kombeng No.27 Tenggarong \\ ${ }^{2,3}$ Fakultas Kehutanan Universitas Mulawarman, Kampus Gunung Kelua Samarinda \\ E-Mail: muliadiunikarta17@gmail.com,yruslim@gmail.com, \\ rkristiningrum@gmail.com
}

\begin{abstract}
ABSTRAK
Analisis Potensi Kayu Bulat Shorea leprosula di Kabupaten Kutai Kartanegara Provinsi Kalimantan Timur. Kerusakan hutan alam dan semakin menurunnya pasokan kayu untuk bahan industri olahan kayu perlu kiranya peningkatan produktivitas hutan diantaranya dengan melaksanakan pembangunan hutan tanaman dipterokarpa dengan jenis Shorea leprosula. Penelitian ini bertujuan untuk (1) mengetahui potensi kayu bulat dan (2) mengetahui hubungan antar variabel berdasarkan analisis bioekonomi Shorea leprosula dengan jarak tanam 3m x 2m yang berlokasi di Kabupatn Kutai Kartanegara dengan luasan plot penelitian seluas 1 ha dengan metode pengambilan sampel tegakan secara systematic random sampling. Analisis data yang digunakan dengan mengukur diameter, tinggi dan volume tegakan setelah itu di analisis secara matematis menggunakan regresi liner sederhana untuk mengetahui hubungan berbagai variabel dengan melihat nilai koefisiensi determinasi $\left(\mathrm{R}^{2}\right)$. Hasil penelitian menunjukkan bahwa total volume dan riap $S$. leprosula jarak tanam $3 \mathrm{~m}$ x $2 \mathrm{~m}$ maksimal dicapai pada umur 47 tahun sebesar $470,09 \mathrm{~m}^{3} / \mathrm{ha}$ dan riap MAI dan CAI berturut-turut sebesar 10,00 dan $10,31 \mathrm{~m}^{3} / \mathrm{ha} / \mathrm{thn}$. Terdapat hubungan keeratan yang tinggi antar variabel bioekonomi umur, diameter, tinggi dan riap dengan koefisien determinasi $\left(\mathrm{R}^{2}\right)$ lebih besar dari $94 \%$.
\end{abstract}

Kata kunci : Potensi, riap, Shorea leprosula.

\begin{abstract}
The potential of Shorea leprosula logs in Kutai Kartanegara Regency, East Kalimantan Province. The destruction of natural forests and the decreasing supply of wood for wood processing industry, it is necessary to increase forest productivity, among others, by developing dipterocarp plantations with the Shorea leprosula species. This study aims to (1) determine the potential of logs and (2) determine the relationship between variables based on the bioeconomic analysis of Shorea leprosula with a spacing of $3 m \times 2 m$ located in Kutai Kartanegara Regency with a research plot area of 1 ha with the stand sampling method was systematic random sampling. Analysis of the data used to measure the diameter, height and volume of stands after that was analyzed mathematically using simple linear regression to determine the relationship between various variables by looking at the coefficient of determination $\left(R^{2}\right)$. The results showed that the total volume and increment of $S$. leprosula, the maximum spacing of $3 m \times 2 m$ was achieved at the age of 47 years 470,09 $\mathrm{m}^{3} / \mathrm{ha}$ and the MAI and CAI increments were 10.00 and $10.31 \mathrm{~m}^{3} /$ ha/year. There is a high relationship between bioeconomic variables with a coefficient of determination $\left(R^{2}\right)$ greater than $95 \%$ and form a supply law curve.
\end{abstract}

Key words : Increment, Potential, Shorea leprosula.

\section{PENDAHULUAN}

Hutan memiliki peranan penting dalam kehidupan manusia sebagai fungsi produksi, lindung, konservasi danlain-lain. Berdasarkan strategi pembangunan jangka panjang kehutanan, hutan yang sudah tidak produktif akan dioptimalkan fungsinya kembali, oleh pemerintah dan hutan dimanfaatkan sebagai hutan tanaman.Hal tersebut telah mampu menarik banyak 
investor karena memiliki nilai ekonomi (benefit) yang tinggi sehingga pengelolaannya dilakukan oleh swasta (pengusaha) dan pemerintah hanya sebagai regulator (Anjasari, 2009).

Penurunan produktivitas hutan alam yang telah mengakibatkan berkurangnya suplai hasil hutan kayu yang dapat dimanfaatkan dalam bidang industri kehutanan. Hal ini mendorong adanya upaya pembangunan Hutan Tanaman sebagai solusi untuk memenuhi suplai bahan baku kayu baik melalui Izin Usaha Pemanfaatan Hasil Hutan Kayu pada Hutan Tanaman Rakyat (IUPHHK-HTR) maupun Izin Usaha Pemanfaatan Hasil Hutan Kayu pada Hutan Tanaman Industri (IUPHHK-HTR). (Kusumaningrum, 2015)

Salah satu faktor yang harus diperhatikan dalam pengelolaan hutan yang lestari yaitu pengetahuan tentang riap, yang mencakup bagaimana cara menghasilkan riap yang optimal serta menganalisanya untuk kepentingan pengelolaan hutan. Pertambahan dalam kurun waktu tertentu baik dalam waktu singkat ataupun periodic (misalnya 1, 5, atau sepuluh tahun) dikenal dengan istilah riap (Ruchaemi, 2013).

Meranti adalah salah satu jenis pohon dari famili Dipterocarpaceae yang mendominasi hutan alam di wilayah Indonesia bagian barat dan tengah (Panjaitan dan Wahyudi, 2011) dengan kualitas kayu yang baik. Jenis ini mendominasi realisasi produksi kayu bulat dari hutan alam dan menjadi primadona industri kayu lapis (plywood) dan wood working di era 80-90 an (Panjaitan dan Wahyudi, 2011). Dengan demikian pengembangan tanaman meranti khususnya $S$. leprosula untuk meningkatkan produktivitas hutan adalah langkah tepat untuk menjawab kelangkaan akan kayu di Indonesia.

Dipterocarpaceae (dipterokarpa) adalah famili dominan penyusun ekosistem hutan alam tropis di Indonesia. Famili dipterokarpa merupakan kelompok tanaman yang memiliki 7 genera atau genus (marga) yaitu Shorea, Parashorea, Hopea, Dryobalanops, Anisoptera, Vatica dan Dipterocarpus. Jumlah spesies dalam keluarga besar dipterocarpa ada sekitar 450 species (Salinding, Y, 2014).

Lebih lanjut, Salinding, Y (2014), 13 dari 16 marga dan 470 dari 510 jenis dari famili dipterokarpa terdapat di Asia Selatan dan Asia Tenggara. Sedangkan genus Shorea yang tumbuh di Indonesia ada sekitar 143 jenis. Berbagai jenis meranti termasuk dalam genus shorea yang dapat dikelompokkan pada empat nama perdagangan yaitu (1) meranti merah, (2) meranti kuning, (3) meranti putih dan (4) balau. Di Indonesia diperkirakan terdapat 270 jenis, tersebar di Kalimantan, Sumatera, Sulawesi, Maluku, Papua, Jawa dan Bali. Di Kalimantan, diperkirakan $67 \%$ dari tegakan pohon yang ada adalah marga shorea. Sedangkan Lebih lanjut, Harsono, B (2014) menjelaskan bahwa dari aspek ekonomi, sebagian besar produksi kayu Indonesia berasal dari jenis-jenis pohon dari famili dipterokarpa, sehingga memiliki nilai ekonomi penting dalam industri kehutanan di Indonesia. Pembangunan tegakan komersil dipterokarpa diutamakan menggunakan jenis-jenis meranti yang cepat tumbuh, penyebarannya luas, telah dikuasai silvikultur penanamannya dan benihnya tersedia. Beberapa jenis meranti yang diprioritaskan untuk pembangunan hutan tanaman komersial antara lain Shorea leprosula, Shorea johorensis, Shorea ovalis, Shorea smithiana dan Shorea platychados.

Menurut Muluk, A (2014), PT Kutai Timber Indonesia (PT KTI) di Kabupaten Kutai Kartanegara Kecamatan Sebulu merupakan salah satu perusahaan yang bergerak dalam bidang industri perkayuan yang berdiri sejak tahun 1991. Dalam areal perkebunan bekas perkebunan dilakukan kegiatan rehabilitasi untuk penelitian 
khususnya jenis dipterokarpa. Kegiatan ini dimulai dari tahun 1991 hingga tahun 2003 seluas 3000 ha. Dalam melaksanakan kegiatan ini bekerjasama dengan Departemen Kehutanan, FORDA (Forest Research and Development Agency/Pusat Penelitian dan Pengembangan Kehutanan), Perusahaan Sumitomo Forestry Co.,Ltd. Dan Universitas Tokyo.

Adanya kerusakan hutan alam dan semakin menurunya pasokan kayu untuk bahan industri olahan kayu dan meningkatnya jumlah kebutuhan akan kayu maka perlu kiranya peningkatan produktivitas hutan diantaranya dengan melaksanakan pembangunan hutan tanaman dipterokarpa dengan jenis Shorea leprosula. Atas dasar itulah kiranya perlu melakukan penelitian untuk mengetahui potensi kayu bulat dan (2) mengetahui hubungan antar variabel berdasarkan analisis bioekonomi Shorea leprosula dengan jarak tanam $3 \mathrm{~m} \times 2 \mathrm{~m}$ yang berlokasi di Kabupaten Kutai Kartanegara.

\section{METODA PENELITIAN}

\subsection{Tempat dan Waktu}

Penelitian dilaksanakan di PT Kutai Timber Kecamatan Sebulu Kabupaten Kutai Kartanegara dengan alasan karena perusahaan tersebut masih mengusahaan tanaman jenis dipterokarpa dan dilaksanakan pada bulan Juni hingga Agustus 2020. Penelitian ini sudah ada di PT Kutai Timber Indonesia sejak tahun 1992/1993, akan tetapi data ini diambil pada umur 27 tahun dalam arti tidak membangun sendiri. Data sebelum umur 27 tahun sudah ada dan setelah itu data baru disimulasikan.

\subsection{Obyek dan Plot Penelitian}

Obyek penelitiannya adalah tegakan jenis $S$. leprosula dengan jarak tanam $3 \mathrm{~m} \times 2 \mathrm{~m}$ pada umur 10, 14, 17, 22 dan 27 tahun, sedangkan umur yang lainya dilakukan simulasi secara sistematis dengan menggunakan uji regersi linier sederhana. Penelitian ini juga didasarkan pada penelitian yang telah dilakukan oleh Kristiningrum (2013) menyatakan bahwa pembentukan model simulasi yang dibentuk secara aritmatik dan operasi logika pada daur hasil dan pemanenan yang berkelanjutan pada hutan dataran rendah dipterokarpa di pulau Kalimantan dapat diestimasi/diperkirakan dengan model regresi linear sederhana. Adapun metode pengambilan datanya secara metode sistematik random sampling dengan luas plot sebesar 1 hektar.

\subsection{Analisis Data}

Penelitian ini menggunakan Microsoft Office Excel untuk melakukan perhitungan volume dan membuat grafik. Analisis tegakan S. leprosula dilakukan dengan menghitung total volume tegakan dan menganalisis riap pertumbuhannya. Pertumbuhan riap adalah pertambahan tumbuh dimensi pohon (tinggi, diameter, luas dasar, dan volume) yang dikaitkan dengan umur pohon atau periode tertentu. Berdasarkan periode pengukuran menurut (Gardingen et. al, 2003), terdapat riap rata-rata tahunan (Mean annual increment/MAI) dan riap ratarata tahunan berjalan (Current annual Increment/CAI) yaitu 


$$
\mathrm{V}=\frac{1}{4} \Pi d^{2} h t f
$$

Dimana $\mathrm{V}=$ volume berdiri, $\mathrm{d}=$ diameter setinggi dada, $\mathrm{h}=$ tinggi bebas cabang, $\mathrm{f}=$ faktor bentuk, sedangkan

$$
\mathrm{MAI}=\frac{V_{t}}{t}
$$

Dimana $:$ MAI $=$ Riap rata-rata tahunan, $\mathrm{Vt}=$ Total volume tegakan pada umur ke $\mathrm{t}, \mathrm{t}=$ umur pohon

$$
\mathrm{CAI}=\frac{V_{t}-V_{t-1}}{T}
$$

Dimana: $\mathrm{CAI}=$ Riapa rata-rata tahunan berjalan, $\mathrm{Vt}=$ Total volume pada umur ke $\mathrm{t}, \mathrm{Vt}-1$ = Total volume pada umur $\mathrm{t}-1, \mathrm{~T}=$ interval waktu antar usia pengukuran.

kemudian antar variabel dianalisis dengan regresi linier sederhana untuk mengetahui koefisisen regresi determinasi $\left(\mathrm{R}^{2}\right)$ untuk mengetahui hubungan keeratan antara variable

\section{HASIL PENELITIAN DAN PEMBAHASAN}

Potensi tegakan kayu yang dihasilkan pada setiap pola pengembangan sangat dipengaruhi oleh jumlah pohon per satuan luas, diameter dan tinggi tanaman, dimana diameter dan tinggi tanaman dipengaruhi oleh faktor eksternal dari tanaman seperti kesuburan tanah dan iklim, sedangkan pola pengembanganya sangat dipengaruhi oleh faktor internal seperti pengetahuan petani tentang jarak tanam, sistem silvikultur dan sebagainya, sehingga potensi tegakan yang dihasilkan pada setiap pola pengembangan akan berlainan (Sawada, 2014).

S. leprosula pada umur 10 tahun memiliki diameter rata-rata sebesar $11 \mathrm{~cm}$. Hal ini berrati pertambahan diameter setiap tahunnya sebesar $1,1 \mathrm{~cm} / \mathrm{thn}$. Setelah umur 10 tahun diameternya mengalami kenaikan hingga $40,2 \mathrm{~cm}$ pada umur 47 tahun. Hal ini berarti pertambahan diameter per tahun sebesar 0,85 cm/thn. Pertambahan diameter S.leprosula pada umur tegakan muda sangat besar, sedangkan semakin tua umur tegakannya, maka pertambahan diameternya semakin menurun. Sedangkan jumlah tegakan per hektar juga mengalami penurunan. Hal ini disebabkan oleh karena adanya tindakan penjarangan dan kematian alami. Tindakan penjarangan ini bertujuan untuk memperbesar diamater dan riap. Hal ini sesuai dengan pernyataan Ruchaemi (2013) bahwa salah satu tujuan dari penjarangan adalah untuk memperbesar riap. Sedangkan rata-rata tinggi bebas cabang S.leprosula pada umur 10 tahun sebesar $7 \mathrm{~m}$ hingga mencapai $14 \mathrm{~m}$ pada umur 57 tahun.

Produksi maksimal S. leprosula dengan jarak tanam $3 \mathrm{~m}$ x $2 \mathrm{~m}$ dicapai pada umur 47 tahun dengan total volume (TV) maksimal yaitu $470,9 \mathrm{~m}^{3} / \mathrm{ha}$, rerata diameter pohon (d) sebesar 40,2 $\mathrm{cm}$ dan tinggi bebas cabang (h) mencapai $12,9 \mathrm{~m}$ sedangkan menurut Muliadi et. al (2017) menyatakan bahwa pengusahaan $S$. leprosula pada jarak tanam $2 \mathrm{~m} \times 2 \mathrm{~m}$ produksi maksimal $S$. leprosula dicapai pada umur 40 tahun berdasarkan analisis bioekonomi hutan dengan menghitung harga kayu bulat, pada umur 40 tahun, total volume (TV) maksimal yaitu 344,22 $\mathrm{m}^{3} /$ ha, keliling tegakan $79,8 \mathrm{~cm}$, rerata diameter pohon (d) sebesar $25,4 \mathrm{~cm}$ dan tinggi bebas cabang (h) mencapai $11,8 \mathrm{~m}$ dengan riap rata-rata tahunan (MAI) mencapai $8,61 \mathrm{~m}^{3} / \mathrm{ha} /$ thn dan riap tahunan berjalan (CAI) mencapai $8,67 \mathrm{~m}^{3} / \mathrm{ha} / \mathrm{thn}$. 
Selanjutnya potensi produksi kayu bulat $S$. leprosula jarak tanam $3 \mathrm{~m} \quad \mathrm{x} \quad 2 \mathrm{~m} \quad 1$.

Tabel 1. Potensi Tegakan S.leprosula Jarak Tanam 3m x $2 \mathrm{~m}$

\begin{tabular}{cccccccc}
\hline Umur & $\mathrm{n}$ & $\mathrm{d}$ & $\mathrm{h}$ & $\mathrm{f}$ & $\mathrm{TV}$ & $\mathrm{MAI}$ & $\mathrm{CAI}$ \\
\hline 10 & 980 & 11,0 & 7,0 & 0,83 & 54,08 & 5,41 & \\
14 & 900 & 14,0 & 8,0 & 0,80 & 88,62 & 6,33 & 8,64 \\
17 & 770 & 17,0 & 8,5 & 0,79 & 117,30 & 6,90 & 9,56 \\
22 & 720 & 21,2 & 8,8 & 0,75 & 167,66 & 7,62 & 10,07 \\
27 & 670 & 26,0 & 8,9 & 0,71 & 224,92 & 8,33 & 11,45 \\
32 & 620 & 30,1 & 9,7 & 0,68 & 291,31 & 9,10 & 13,28 \\
37 & 560 & 34,5 & 10,9 & 0,63 & 358,46 & 9,69 & 13,43 \\
42 & 520 & 37,5 & 11,8 & 0,62 & 418,54 & 9,97 & 12,02 \\
$\mathbf{4 7}$ & $\mathbf{4 7 0}$ & $\mathbf{4 0 , 2}$ & $\mathbf{1 2 , 9}$ & $\mathbf{0 , 6 1}$ & $\mathbf{4 7 0 , 0 9}$ & $\mathbf{1 0 , 0 0}$ & $\mathbf{1 0 , 3 1}$ \\
52 & 450 & 42,0 & 13,4 & 0,60 & 501,17 & 9,64 & 6,22 \\
57 & 400 & 45,0 & 14,0 & 0,58 & 516,31 & 9,06 & 3,03 \\
\hline
\end{tabular}

Keterangan: $\mathrm{n}=$ individu pohon, $\mathrm{d}=$ diameter $(\mathrm{cm}), \mathrm{h}=$ tinggi $(\mathrm{m}), \mathrm{TV}=$ total volume $\left(\mathrm{m}^{3} / \mathrm{ha}\right)$, MAI $=$ mean annual increment/riap rata-rata tahunan $\left(\mathrm{m}^{3} / \mathrm{ha} / \mathrm{thn}\right)$, CAI = Current Annual Increment/riap tahun berjalan $\left(\mathrm{m}^{3} / \mathrm{ha} / \mathrm{thn}\right)$

Pada Tabel 1 dapat dijelaskan bahwa produksi maksimal $S$. leprosula dengan jarak tanam $3 \mathrm{~m} \times 2 \mathrm{~m}$ dicapai pada umur 47 tahun, riap maksimum rata-rata tahunan (MAI) mencapai $10,00 \mathrm{~m}^{3} /$ ha/thn dan riap tahunan berjalan (CAI) mencapai 10,31 $\mathrm{m}^{3} / \mathrm{ha} / \mathrm{thn}$ serta jumlah pohon sebanyak 470 pohon. Sedangkan setelah umur 52 tahun sampai umur 57 tahun riapnya mengalami penurunan dari 9,64 menjadi $9,06 \mathrm{~m}^{3} / \mathrm{ha} / \mathrm{thn}$. Dan jumlah pohon per hektar dari 450 pohon/ha menjadi 400 pohon/ha. Hal ini sejalan dengan Soares (2018) yang menyatakan bahwa pertumbuhan tanaman dipterokarpa jenis

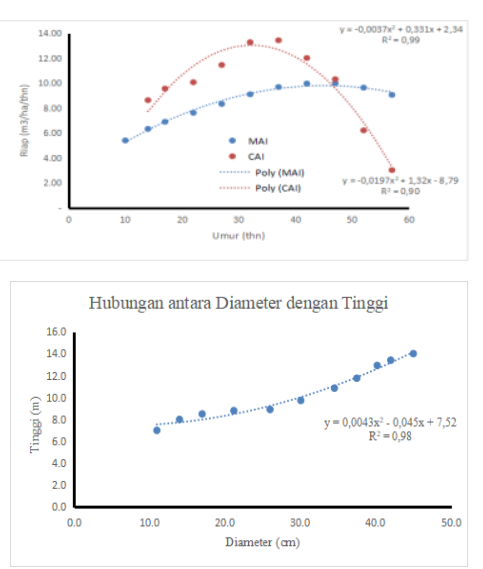

Shorea leprosula mempunyai riap maksimal pada umur 40 tahun, dengan total volume $311,22 \mathrm{~m}^{3} / \mathrm{ha}$, sehingga diperoleh MAI mencapai $7,78 \mathrm{~m}^{3} / \mathrm{ha} / \mathrm{thn}$ dan CAI mencapai $7,81 \mathrm{~m}^{3} / \mathrm{ha} / \mathrm{thn}$ dan berkurangnya jumlah pohon setiap tahun disebabkan oleh kematian alami dan penjarangan.

Grafik pertumbuhan riap rata-rata tahunan (MAI) dan riap tahunan berjalan (CAI) kayu $S$. leprosula dengan jarak tanam $3 \mathrm{~m} \times 2 \mathrm{~m}$ berdasarkan data pada Tabel 1 dapat diestimasi secara sistematis disajikan pada Gambar 1.

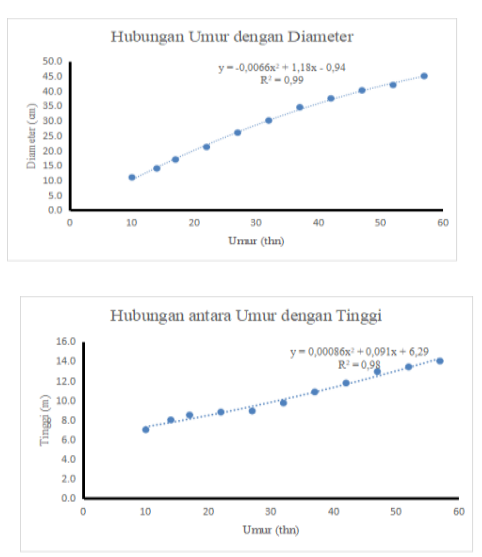

Gambar 1. MAI dan CAI dan Hubungan Berbagai VariabelS. leprosula pada Jarak Tanam $3 \mathrm{~m} \times 2 \mathrm{~m}$ 
Menurut Dinga (2014), Muliadi et al. (2017) dan Winarni et al. (2017), Kristiningrum, dkk (2019) grafik menunjukkan karakteristik tertentu, sebagai berikut: kurva CAI dengan cepat mencapai puncak dan dari sana langsung menurun, sedangkan kurva MAI naik dan turun secara perlahan. Dari grafik pertambahan volume tegakan pohon $S$. leprosula pada Gambar 1 terlihat bahwa pada awalnya MAI lebih rendah dari CAI, dan CAI mencapai puncak sebelum MAI. Setelah mencapai puncak, CAI menurun dan pada titik tertentu berpotongan dengan MAI. Titik potong MAI dan CAI terjadi pada usia 47 tahun. Setelah titik persimpangan, baik MAI maupun CAI menurun, menunjukkan tren penurunan dalam peningkatan volume. Pada umur 47 tahun, rerata riap volume tegakan tahunan $S$. leprosula telah mencapai maksimum, yang menunjukkan bahwa potensi produksi kayu maksimal telah tercapai dan pohon tersebut siap untuk ditebang.

Pada gambar diatas dapat dijelaskan bahwa riap rata-rata tahunan mengalami kenaikan setiap tahunnya dari $5,41 \mathrm{~m}^{3} / \mathrm{ha} / \mathrm{thn}$ pada umur 10 tahun hingga mencapai puncak maksimal sebesar $10,00 \mathrm{~m}^{3} / \mathrm{ha} /$ thn pada umur 47 tahun dan setelah itu mengalami penurunan. Sedangkan riap rata-rata tahunan berjalan mengalami kenaikan juga dari $8,64 \mathrm{~m}^{3} / \mathrm{ha} /$ thn pada umur 14 tahun hingga mencapai puncak maksimal sebesar $13,43 \mathrm{~m}^{3} / \mathrm{ha} /$ thn pada umur 37 tahun dan setelah itu mengalami penurunan dan bertemu pada satu titik perpotongan sebesar $10,31 \mathrm{~m}^{3} / \mathrm{ha} / \mathrm{thn}$ pada umur 47 tahun dan setelah itu mengalami penurunan riap hingga 3,03 $\mathrm{m}^{3} /$ ha/thn pada umur 57 tahun. Hal ini berarti tegakan S. leprosula siap ditebang pada umur 47 tahun dengan diameter sebesar 40,2 $\mathrm{cm}$ dan riap sebesar 10 $\mathrm{m}^{3} /$ ha/thn dan $10,31 \mathrm{~m}^{3} / \mathrm{ha} /$ thn. Hal ini berarti bahawa besarnya riap dai pengaruhi juga oleh kerapatan dan kesuburan tanah. Hal ini selaras dengan pernyataan Noor et al (2019) menyatakan bahwa besarnya riap ratarata tahunan maksimal tergantung dari kerapatan/jumlah pohon per hektar, jenis tanaman dan tingkat kesuburan tanah.

Untuk mengetahui keeratan suatu hubungan pada berbagai variabel berdasarkan Tabel 1. Maka dengan menggunakan persamaan regresi polynomial yang menunjukan nilai koefisien determinasi $\left(\mathrm{R}^{2}\right)$ (Gardingan et al. 2003). Nilai koefisien determinasi $\left(\mathrm{R}^{2}\right)$ menunjukkan tingkat ketelitian dan keeratan hubungan yang signifikan antar variabel bebas dengan variabel tak bebasnya $\left(\mathrm{R}^{2}>0,95\right)$, pengujian yang dilakukan menurut kriteria ini akan lebih dapat menambah keyakinan penerimaan kearifan lokal yang akurat. Semakin tinggi nilai koefisien regresi, maka semakin erat hubungan antar variabel (Arezoo et al, 2014). Berdasarkan Gambar 1, dapat lihat hubungan kereatan antara umur dengan riap. Hubungan antara umur dengan riap rata-rata tahun (MAI) memiliki koefisien regresi sebesar $98 \%$. sedangkan koefisien regresi hubungan umur dengan riap rata-rata tahunan berjalan (CAI) sebesar 90\%. Hal ini berarti rata-rata koefisien regresi untuk MAI dan CAI sebesar $94 \%$ yang berarti bahwa $94 \%$ umur mempengaruhi pertumbuhan riap, sedangkan $6 \%$ di pengaruhi oleh faktor yang lain.

Dari Gambar 1 dapat dijelaskan juga bahwa telah terjadi suatu hubungan keeratan yang tinggi antara masingmasing variabel $S$. leprosula jarak tanam $3 \mathrm{~m} \quad \mathrm{x} \quad 2 \mathrm{~m} \quad$ berdasarkan analisis bioekonomi hubungan naara umur dengan tinggi tegakan, umur dengan diameter tegakan dan hubungan antara diameter dan tinggi. Ternyata hubungan antar variabel tersebut memiliki koefisien 
determinasi rata-rata diatas $98 \%$. Hal ini artinya telah terjadi hubungan keeratan yang tinggi pada keempat model tersebut diatas. Namun jika masing-masing variabel hubungan telah membentuk suatu kurva, ternyata ada dua jenis model kurva berdasarkan kaidah ilmiah, yaitu kurva penawarandan permintaan. Grafik hubungan antara umur dengan diameter, umur dengan tinggi dan hubungan antara diameter dan tinggi membentuk kurva penawaran. Hal ini berarti bahwa hubungan antara variabel bioekonomi telah memenuhi kaidah ilmiah yang telah ada yaitu sesuai dengan hukum penawaran

\section{KESIMPULAN}

Kesimpulan dari hasil penelitian adalah sebagai berikut bahwa produksi maksimal $S$. leprosula dengan jarak tanam $3 \mathrm{~m} \times 2 \mathrm{~m}$ dicapai pada umur 47 tahun, riap maksimum rata-rata tahunan (MAI) mencapai $10,00 \mathrm{~m}^{3} / \mathrm{ha} /$ thn dan riap tahunan berjalan (CAI) mencapai 10,31 $\mathrm{m}^{3} /$ ha/thn serta jumlah pohon sebanyak 470 pohon. Terdapat hubungan keeratan yang tinggi antar variabel bioekonomi dengan koefisien determinasi $\left(\mathrm{R}^{2}\right)$ ratarata sebesar dari 94\%. Hal ini berrati terdapat hubungan keeratan yang tinggi antara variabel umur, diameter, tinggi dan riap.

\section{DAFTAR PUSTAKA}

Anjasari, R. (2009). Pengaruh Hutan Tanaman Industri (HTI) terhadap Kondisi Sosial Ekonomi Masyarakat di Kecamatan Kampar Ilir.Tugas Akhir Jurusan Perencanaan Wilayah dan Kota. Fakultas Teknik Universitas Diponegoro, Semarang.
Arezoo S, Sankhayan PL, Hofstad O. (2014). A Dynamic Bio-Economic Model for Community Management of Goat and Oak Forests in Zagros, Iran. Journal Ecology Economy, 106: 174-185.

Dinga, E. (2014). On a Possible Predictor of The Cyclical Position of The Economy. Procedia Econ Finance, 254-261.

Gardingen V, McLeish, Philips P, Fadilah D, Tyrie G,Yasman I. (2003). Financial and Ecological Analysis of Management Options for Logged-over Dipterocarp Forest in Indonesia Borneo. Forest Ecology Management: 1-29.

Harsono, B. (2014). Simulasi Produksi Kayu Bulat dan Aspek Ekonomi Usaha Tanaman Jenis Shorea parvifolia Dan Dryobalanops lanceolata di PT Kutai Timber Indonesia (PT KTI). Skripsi. Samarinda : Fakultas Kehutanan Universitas Mulawarman.

Winarni B, Lahjie A.M., B.D.A.S. Simarangkir, Ruslim, Y. (2017). Tengkawang Cultivation Model in Community Forest Using Agroforestry System in West Kalimantan, Indonesia. Biodiversitas , 765-772.

Kristiningrum R, Lahjie A, Masjaya, Yusuf S., Ruslim Y. (2019). Species Diversity, Stand Productivity, Aboveground Biomass and Economic Value of Mangrove Ecosystem in Mentawir Village, East Kalimantan, Indonesia. Biodiversitas. 20 (10): 2848-2857

Kristiningrum, R. (2013). Simulasi Pertumbuhan Dan Finansial Hutan Tanaman Dipterokarpa Dengan Teknik Silvikultur Intensif (Silin) di PT Balikpapan Forest Industries 
(PT BFI). Tesis. Samarinda: Fakultas Kehutanan Universitas Mulawarman.

Kusumaningrum. (2015). Analisis Kelayakan Finansial dan Ekonomi Pada Hutan Tanaman Industri PT Silva Nusantara Investama. Jogyakarta: Universitas Gadjah Mada.

Lahjie A.M., Lepong A., B.D.A.S. Simarangkir, R. Kristiningrum, Ruslim, Y. (2016). Financial analysis of dipterocarp log production and rubber production in the forest and lang rehabilitation program of Sekolaq Muliaq, West Kutai District, Indonesia. Biodiversitas 19 (3): 677-686.

Muluk, Abdul. (2014). Simulasi Kayu Bulat Dan Investasi Shore leprosula di PT. Kutai Timber Indonesia. Tesis. Samarinda: Fakultas Kehutanan Universitas Mulawarman.

Muliadi, M., Lahjie A.M., B.D.A.S. Simarangkir, Ruslim, Y. (2016). Bioeconomic and enviromental valuation of dipterocarp estate forest based on local wisdom in Kutai Kertanegara, Indonesia. Biodiversitas 19 (1): 401-408.

Noor, R., Lahjie, A.M., Simarangkir., Ruslim, Y. (2019). Analisis Peluang Usaha Bagi Hasil Hutan Tanaman Jenis Eucalyptus pellita F Muel dan Accacia mangium di Kabupaten Kutai Kartanegara Provinsi Kalimantan Timur.Agrifor, 18(2), 313-324.

Pamoengkas, $P$ dan Juniar. (2011). Pertumbuhan Meranti Merah (Shorea leprosula Miq) dalam
Sistem Silvikultur Tebang Pilih Tanam Jalur (Studi Kasus di Areal IUPHHK-HA PT Sari Bumi Kusuma, Kalimantan Tengah. Jurnal Silvikultur Tropika 2(1), 9 13.

Ruchaemi, A. (2013). Ilmu Pertumbuhan Hutan. Samarinda: Mulawarman University Press.

Salinding, Y. (2014). Simulasi Produksi Kayu Bulat dan Aspek Ekonomi Usaha Tanaman Jenis Shorea leprosula Dan Shorea siminis Di PT Kutai Timber Indonesia (PT KTI). Skripsi. Samarinda : Fakultas Kehutanan Universitas Mulawarman.

Sawada, M. (2014). Analisis Pertumbuhan dan Kelayakan Finansial Hutan Tanaman Jenis Dipterokarpa dengan RSSI Sebagai Model Pengelolaan Hutan Alam Berkelanjutan di Provinsi Kalimantan Timur. Disertasi. Samarinda: Program Doktor Ilmu Kehutanan Fakultas Kehutanan Universitas Mulawarman.

Soares, M., Lahjie A.M., Simarangkir., Ruslim Y. (2019). Analisis Produksi Kayu Bulat dan Peluang Usaha Bagi Hasil Jenis Shorea leprosula Dan Shorea smithiana di PT Inhutani I Bukit Bangkirai Balikpapan. Agrifor, 18(1), 1-12.

Winarni B, Lahjie AM, Simarangkir BDAS, Yusuf S, Ruslim Y. (2017). Tengkawang Cultivation Model in Community Forest Using Agroforestry System in West Kalimantan, Indonesia. Biodiversitas 18 (2):765-772 